\title{
Predictors of long-term adverse events after Absorb bioresorbable vascular scaffold implantation: a 1,933-patient pooled analysis from international registries
}

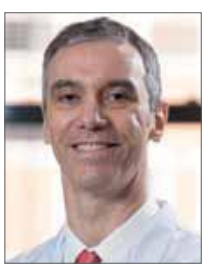

\author{
Adriano Caixeta ${ }^{1 *}, \mathrm{MD}, \mathrm{PhD}$; Carlos M. Campos ${ }^{1}, \mathrm{MD}, \mathrm{PhD}$; Cordula Felix ${ }^{2}, \mathrm{MD}$; \\ Alaide Chieffo ${ }^{3}, \mathrm{MD}$; Piera Capranzano ${ }^{4}$, MD; Hiroyoshi Kawamoto ${ }^{3}, \mathrm{MD}$; \\ Claudia Tamburino ${ }^{4}, \mathrm{MD}$; Roberto Diletti ${ }^{2}, \mathrm{MD}$; José de Ribamar Costa $\mathrm{Jr}^{5}, \mathrm{MD}, \mathrm{PhD}$; \\ Yoshinobu Onuma², MD, PhD; Robert-Jan van Geuns², MD; Antonio L. Bartorelli ${ }^{6}$, MD; \\ Antonio Colombo ${ }^{3}, \mathrm{MD}$; Corrado Tamburino ${ }^{4}, \mathrm{MD}$; Patrick W. Serruys ${ }^{7}, \mathrm{MD}, \mathrm{PhD}$; \\ Alexandre Abizaid ${ }^{1,5}, \mathrm{MD}, \mathrm{PhD}$
}

1. Hospital Israelita Albert Einstein, São Paulo, Brazil; 2. Department of Cardiology, Thoraxcenter, Erasmus Medical Center, Rotterdam, the Netherlands; 3. Interventional Cardiology Unit, San Raffaele Scientific Institute, Milan, Italy; 4. Division of Cardiology, Ferrarotto Hospital, University of Catania, Catania, Italy; 5. Instituto Dante Pazzanese de Cardiologia, São Paulo, Brazil; 6. Centro Cardiologico Monzino, IRCCS, University of Milan, Milan, Italy; 7. International Centre for Circulatory Health, NHLI, Imperial College London, London, United Kingdom

A. Caixeta and C.M. Campos contributed equally to this work.

GUEST EDITOR: Alec Vahanian, MD, PhD; Department of Cardiology, Hôpital Bichat-Claude Bernard, and University Paris VII, Paris, France

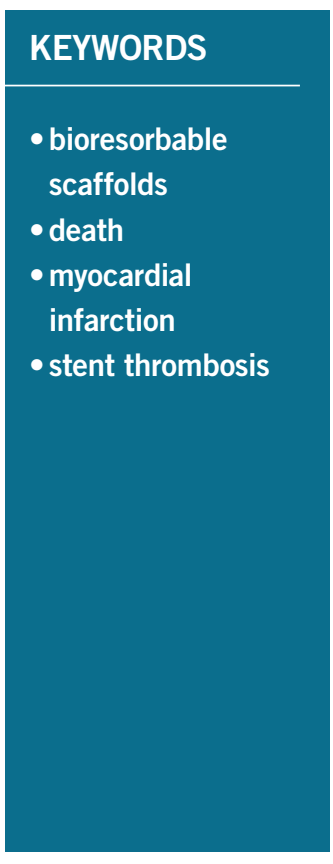

\begin{abstract}
Aims: The aim of this study was to investigate the predictors of long-term adverse clinical events after implantation of the everolimus-eluting Absorb bioresorbable vascular scaffold (BVS).

Methods and results: We pooled patient-level databases derived from the large-scale ABSORB EXTEND study and five high-volume international centres. Between November 2011 and November 2015, 1,933 patients underwent PCI with a total of 2,372 Absorb BVS implanted. The median age was 61.0 (IQR 53.0 to 68.6 ) years, $24 \%$ had diabetes, and $68.2 \%$ presented with stable coronary artery disease. At a median follow-up of 616 days, MACE occurred in 93 (4.9\%) patients, all-cause death in 36 (1.9\%) patients, myocardial infarction in $47(2.5 \%)$ patients, and target vessel revascularisation in $72(3.8 \%)$ patients. Definite or probable scaffold thrombosis occurred in $26(1.3 \%)$ patients. On multivariable logistic regression analysis, acute coronary syndromes (hazard ratio [HR] 2.79, 95\% confidence interval [CI]: 1.47 to 5.29; $\mathrm{p}=0.002$ ), dyslipidaemia (HR 1.43, 95\% CI: 1.23 to $1.79 ; \mathrm{p}=0.007$ ), scaffold/reference diameter ratio $>1.25$ (HR 1.49, 95\% CI: 1.18 to $1.88 ; \mathrm{p}=0.001$ ), and residual stenosis $>15 \%$ (HR $1.67,95 \%$ CI: 1.34 to $2.07 ; \mathrm{p}<0.001$ ) were independent predictors of MACE, whereas the use of intravascular imaging was independently associated with a reduction in MACE (HR 0.13, 95\% CI: 0.06 to 0.28 ; $\mathrm{p}<0.001$ ).
\end{abstract}

Conclusions: Optimal Absorb BVS implantation and the use of intravascular imaging guidance are associated with lower rates of adverse events at long-term follow-up.

\footnotetext{
*Corresponding author: Department of Cardiovascular Intervention, Hospital Israelita Albert Einstein, Av. Albert Einstein, 627,
} Morumbi, São Paulo 05652-000,Brazil.E-mail: adriano.caixeta@einstein.br 


\section{Abbreviations}

BVS bioresorbable vascular scaffold(s)

DES drug-eluting stent(s)

EES everolimus-eluting metallic stent

MACE major adverse cardiac events

MI myocardial infarction

PCI percutaneous coronary intervention

PSP predilation, sizing, and post-dilation

\section{Introduction}

Over the past few decades, drug-eluting stents (DES) have become the gold standard for the treatment of coronary artery disease; however, the permanent metallic structure and polymer left within the coronary artery wall have been associated with incomplete endothelialisation, chronic inflammation, toxicity, loss of normal vessel curvature, impaired vasomotion, stent fracture, and neoatherosclerosis ${ }^{1}$. This could lead to a long-term risk of adverse events including myocardial infarction (MI), target lesion revascularisation, stent thrombosis, and death at a rate of approximately $2.5 \%$ annually ${ }^{2}$. As a result, fully bioresorbable vascular scaffolds (BVS) have emerged as a promising alternative to metallic DES, with the goal of achieving better long-term results ${ }^{3}$.

Since the introduction of the everolimus-eluting Absorb ${ }^{\mathrm{TM}}$ BVS (Abbott Vascular, Santa Clara, CA, USA) in 2011, over 150,000 procedures in more than 100 countries have been performed using the device (data on file at Abbott Vascular as of April 2017). Recent studies have raised safety concerns about the Absorb, specifically regarding higher rates of device thrombosis compared with $\mathrm{DES}^{4-7}$. Of note, scaffold thrombosis has been reported to occur relatively early (within 30 days), suggesting that implantation technique rather than delayed healing may play a major role. Absorb is a balloon-expandable bioresorbable poly-L-lactide scaffold that has relatively thick struts $(157 \mu \mathrm{m}$ versus $70-80 \mu \mathrm{m}$ in metallic DES); an appropriate implantation technique including predilation, sizing, and post-dilation (PSP) has been recommended for optimal device implantation ${ }^{6,89}$. The importance of vessel size selection comes from the ABSORB III trial ${ }^{5,6}$, in which the overall rate of scaffold thrombosis was twofold higher in patients treated with the Absorb BVS compared with those receiving an everolimus-eluting metallic stent (EES). When small $(<2.25 \mathrm{~mm})$ vessels were excluded, the rate of device thrombosis was similar between groups. In addition, when optimal/PSP technique for BVS implantation was performed, rates of target lesion failure and scaffold thrombosis were similar with Absorb compared with EES. Hence, procedure-related factors such as lesion selection and preparation, vessel sizing, and scaffold post-implantation dilation seem to be of paramount importance for Absorb implantation. In a post $h o c$ analysis, we sought to investigate the predictors of adverse events at long-term follow-up from a pooled patient-level database of the large-scale ABSORB EXTEND study and high-volume international centres.

\section{Methods}

We pooled patient-level databases derived from the ABSORB EXTEND ( $\mathrm{n}=812$ from January 2010 to October 2013) study and five high-volume international centres (Hospital Israelita Albert Einstein, São Paulo, Brazil [n=120 from November 2014 to June 2015]; San Raffaele Scientific Institute, Milan, Italy [ $\mathrm{n}=223$ from May 2013 to May 2015]; Ferrarotto Hospital, University of Catania, Catania, Italy [ $\mathrm{n}=392$ from March 2013 to June 2014]; Thoraxcenter, Erasmus Medical Center, Rotterdam, the Netherlands [ $\mathrm{n}=356$ from September 2012 to December 2015]; Instituto Dante Pazzanese de Cardiologia, São Paulo, Brazil [n=30 from January 2015 to June 2015]). Between November 2011 and November 2015, 1,933 patients underwent percutaneous coronary intervention (PCI) with a total of 2,372 Absorb BVS implanted. ABSORB EXTEND $(\mathrm{N}=812)$ was a global registry with a goal of expanding experience with the Absorb BVS system to different geographies with broader inclusion criteria in order to include the treatment of longer lesions and multiple vessels ${ }^{10}$. The five highvolume international centres $(\mathrm{N}=1,121)$ involved in the post hoc analysis included unselected "real-world" patients treated with the Absorb BVS. The choice of Absorb implantation in each centre was based on operator discretion and device availability, not on any specific institutional protocol. Intravascular imaging (optical coherence tomography [OCT] or intravascular ultrasound [IVUS]) was performed at the discretion of the operator at each participating centre.

\section{DEFINITIONS}

Reference vessel diameter, lesion length, and in-scaffold percent stenosis were assessed by online quantitative coronary angiography and were captured from the ABSORB EXTEND study data set and each individual centre. "Absorb oversize" was defined as when the vessel diameter was smaller than the nominal size of the implanted scaffold (scaffold/reference vessel ratio $>1$ ).

We assessed 30-day and long-term rates of all-cause death, MI, major adverse cardiac events (MACE - a combination of death, target vessel MI, or clinically driven target vessel revascularisation), and definite/probable scaffold thrombosis. Scaffold thrombosis was classified according to the Academic Research Consortium definition as definite or probable ${ }^{11}$. Q-wave MI was the development of a new, pathological Q-wave. Non-Q-wave MI was defined as elevation of creatine kinase levels to $\geq 2$ times the upper limit of normal with elevated CK-MB in the absence of new pathological Q-waves. Ischaemia-driven target lesion revascularisation was defined as any repeat percutaneous intervention or bypass surgery.

\section{STATISTICAL ANALYSIS}

Discrete data were summarised as percent (frequencies) and compared by $\chi^{2}$ analysis or Fisher's exact test. Continuous data were expressed as mean \pm standard deviation or median and interquartile range based on their distribution and compared using the Wilcoxon rank-sum test. Time-to-event variables are presented 
as Kaplan-Meier estimates and compared using the log-rank test at a median follow-up of 616 days. Multivariable analyses were conducted with a Cox regression model for the occurrence of MACE, using all variables shown in Table 1 and Table 2. The set of variables with a $p$-value $\leq 0.10$ in the univariate regression analyses was included in the multivariable regression analyses. After discarding variables that showed collinearity, multivariable models were created using a selection of clinically and procedurally relevant variables in order to avoid overfitting. The following covariates were selected for inclusion in the Cox analysis: clinical - female sex, age, family history of premature coronary artery disease, hypertension, diabetes, dyslipidaemia, prior MI, prior PCI, creatinine clearance, and acute coronary syndromes; procedural - reference vessel diameter, scaffold diameter, intravascular imaging utilisation, post-dilatation pressure, scaffold/reference diameter ratio $>1.25$, and post-procedure stenosis $>15 \%$. Forward selection was used, and the entry and stay criteria were set to 0.05 . Receiver operating characteristic (ROC) curves were constructed to assess the predictive accuracy of the scaffold oversize and final residual stenosis for 30-day and long-term adverse events. The minimum absolute value of sensitivity-specificity for these variables was chosen as the optimal ROC cut-off point. The pattern of missing data shown was arbitrary. Missing data were then approached using multiple imputation with regression model analysis; this was carried out five times. The highest percentage of missing data was $8 \%$. Follow-up of the patients was censored in April 2014 for ABSORB EXTEND and in November 2015 or at the last known event-free time point (whichever came first) for the other sites. All statistical tests were two-tailed. Statistical significance was set at a level of 0.05. SPSS, Version 21.0 (IBM Corp., Armonk, NY, USA) was used for all statistical analyses.

\section{Results}

\section{PATIENTS, PROCEDURES, AND ADVERSE EVENTS}

The median age was 61.0 years (interquartile range 53.0 to 68.6 ), $24 \%$ had diabetes, $68.2 \%$ presented with stable coronary artery disease, and $67.9 \%$ had single-vessel coronary artery disease (Table 1). As shown in Table 2, 97\% of the lesions were de novo, $19.3 \%$ were bifurcations, and $18.1 \%$ had severe calcification. The median total length of the implanted scaffold was $18.0 \mathrm{~mm}$ (interquartile range 18.0-28.0), scaffolds overlapped in $22.3 \%$ of cases, post-dilatation was performed in $75.6 \%$, and a final Thrombolysis In Myocardial Infarction (TIMI) 3 flow was attained in $98.7 \%$. Compared with patients without MACE, those with MACE were more often women, more frequently non-smokers, and had higher rates of prior MI, prior PCI, American College of Cardiology (ACC)/American Heart Association (AHA) class B2 lesions, reference diameter $<2.5 \mathrm{~mm}$, smaller scaffold diameter, scaffold/reference diameter ratio $>1.25$, and post-procedure stenosis $>15 \%$.

At a median follow-up of 616 days, MACE occurred in 93 $(4.9 \%)$ patients, all-cause death in $36(1.9 \%)$ patients, MI in 47 $(2.5 \%)$ patients, and target vessel revascularisation in $72(3.8 \%)$ patients. Definite or probable scaffold thrombosis occurred in 26 (1.3\%) patients (Figure 1, Table 3).

Table 1. Patient baseline clinical characteristics according to the occurrence of MACE.

\begin{tabular}{|c|c|c|c|c|c|}
\hline & Overall $(n=1,933)$ & No MACE $(n=1,896)$ & MACE $(n=37)$ & p-value \\
\hline \multicolumn{2}{|l|}{ Age, years } & $61.0(53.0-68.6)$ & $61.4(53.1-69.0)$ & $64.5(56.6-70.5)$ & 0.16 \\
\hline \multicolumn{2}{|l|}{ Male } & $1,526(78.9 \%)$ & $1,504(79.3 \%)$ & $22(59.5 \%)$ & 0.007 \\
\hline \multicolumn{2}{|c|}{ Body mass index } & $26.8(24.4-29.6)$ & $26.8(24.4-29.7)$ & $26.6(23.6-29.5)$ & 0.74 \\
\hline \multicolumn{2}{|c|}{ Current smoker } & $459(23.7 \%)$ & $454(23.9 \%)$ & $5(13.5 \%)$ & 0.10 \\
\hline \multicolumn{2}{|c|}{ Hypertension } & $1,273(65.9 \%)$ & $1,244(65.6 \%)$ & $29(78.4 \%)$ & 0.12 \\
\hline \multicolumn{2}{|l|}{ Diabetes } & $463(24.0 \%)$ & $451(23.8 \%)$ & $12(32.4 \%)$ & 0.24 \\
\hline \multicolumn{2}{|c|}{ Insulin-requiring } & $108(5.6 \%)$ & $105(5.5 \%)$ & $3(8.1 \%)$ & 0.46 \\
\hline \multicolumn{2}{|c|}{ Dyslipidaemia } & $1,201(62.1 \%)$ & $1,172(61.8 \%)$ & $29(78.4 \%)$ & 0.06 \\
\hline \multicolumn{2}{|c|}{ Previous myocardial infarction } & $368(19 \%)$ & $352(18.6 \%)$ & $16(43.2 \%)$ & 0.001 \\
\hline \multicolumn{2}{|c|}{ Previous $\mathrm{PCl}$} & $523(27.1 \%)$ & $507(26.7 \%)$ & $16(43.2 \%)$ & 0.04 \\
\hline \multicolumn{2}{|c|}{ Previous CABG } & $48(2.5 \%)$ & $48(2.5 \%)$ & $0(0.0 \%)$ & 1.00 \\
\hline \multirow{3}{*}{$\begin{array}{l}\text { Number of } \\
\text { diseased } \\
\text { vessels }\end{array}$} & 1 & $1,312(67.9 \%)$ & $1,289(68.0 \%)$ & $23(62.2 \%)$ & \multirow{3}{*}{0.29} \\
\hline & 2 & $458(23.7 \%)$ & $447(23.6 \%)$ & $11(29.7 \%)$ & \\
\hline & 3 & $163(8.4 \%)$ & $160(8.4 \%)$ & $3(8.1 \%)$ & \\
\hline \multirow{4}{*}{$\begin{array}{l}\text { Clinical } \\
\text { presenta- } \\
\text { tion }\end{array}$} & Stable coronary artery disease & $1,168(60.4 \%)$ & $1,141(60.2 \%)$ & $27(73.0 \%)$ & 0.09 \\
\hline & Unstable angina & $391(20.2 \%)$ & $384(20.3 \%)$ & $7(18.9 \%)$ & 1.00 \\
\hline & Non-STEMI & $208(10.7 \%)$ & 206 (10.9\%) & $2(5.4 \%)$ & 0.73 \\
\hline & STEMI & $166(8.6 \%)$ & $165(8.7 \%)$ & $1(2.7 \%)$ & 0.52 \\
\hline
\end{tabular}

Values are median (interquartile range) or $n$ (\%). CABG: coronary artery bypass graft; MACE: major adverse cardiac events; PCl: percutaneous coronary intervention; STEMI: ST-elevation myocardial infarction 
Table 2. Lesion and procedural characteristics according to the occurrence of MACE.

\begin{tabular}{|c|c|c|c|c|c|}
\hline \multicolumn{2}{|l|}{$\ln ^{2}$} & Overall $(n=2,372)$ & No MACE $(n=2,280)$ & MACE $(n=92)$ & $p$-value \\
\hline \multicolumn{2}{|l|}{ De novo lesion } & 97.0 & 97.0 & 96.7 & 0.76 \\
\hline \multirow[t]{4}{*}{ Lesion complexi } & $A$ & 6.5 & 7.0 & 1.1 & \multirow{4}{*}{0.007} \\
\hline & B1 & 38.8 & 40.4 & 31.8 & \\
\hline & B2 & 37.3 & 37.9 & 54.5 & \\
\hline & C & 14.1 & 14.7 & 12.5 & \\
\hline \multirow{4}{*}{$\begin{array}{l}\text { Pre-procedure T } \\
\text { flow }\end{array}$} & 0 & 7.2 & 7.2 & 8.4 & \multirow{4}{*}{0.15} \\
\hline & 1 & 1.5 & 1.6 & 0.0 & \\
\hline & 2 & 8.1 & 8.3 & 2.4 & \\
\hline & 3 & 83.2 & 82.9 & 89.2 & \\
\hline \multicolumn{2}{|l|}{ Bifurcation } & 19.3 & 19.1 & 25.0 & $<0.001$ \\
\hline \multicolumn{2}{|l|}{ Severe tortuosity } & 1.6 & 2.5 & 3.5 & 0.49 \\
\hline \multicolumn{2}{|c|}{ Severe calcification } & 18.1 & 18.1 & 20.9 & 0.49 \\
\hline \multicolumn{2}{|c|}{ Angiographic thrombus } & 2.9 & 3.7 & 2.3 & 0.77 \\
\hline \multicolumn{2}{|c|}{ Chronic total occlusion } & 3.2 & 4.0 & 2.2 & 0.58 \\
\hline \multicolumn{2}{|c|}{ Diameter stenosis, \% } & $67.0(56.0-80.0)$ & $67.0(55.0-80.0)$ & 61.5 (55.9-73.5) & 0.09 \\
\hline \multicolumn{2}{|c|}{ Lesion length, mm } & $14.0(10.0-19.5)$ & $14.4(10.1-22.0)$ & $15.2(10.0-20.1)$ & 0.75 \\
\hline \multicolumn{2}{|c|}{ Proximal reference diameter, $\mathrm{mm}$} & $2.91(2.66-3.23)$ & $2.92(2.66-3.23)$ & $2.79(2.45-3.08)$ & 0.02 \\
\hline \multicolumn{2}{|c|}{ Distal reference diameter, $\mathrm{mm}$} & $2.60(2.36-2.90)$ & $2.61(2.36-2.90)$ & $2.48(2.12-2.80)$ & 0.002 \\
\hline \multicolumn{2}{|c|}{ Predilatation } & 96.9 & 96.9 & 98.9 & 0.52 \\
\hline \multicolumn{2}{|c|}{ Number of scaffolds } & $1.0(1.0-1.0)$ & $1.0(1.0-1.0)$ & $1.0(1.0-2.0)$ & 0.01 \\
\hline \multicolumn{2}{|c|}{ Concomitant metallic stent } & 11.9 & 11.8 & 16.7 & 0.33 \\
\hline \multicolumn{2}{|c|}{ Number of metallic stents } & $0.18 \pm 0.55$ & $0.17 \pm 0.54$ & $0.33 \pm 0.90$ & 0.25 \\
\hline \multicolumn{2}{|l|}{ OCT use } & 16.1 & 17.0 & 8.8 & 0.19 \\
\hline \multicolumn{2}{|l|}{ IVUS use } & 14.9 & 13.7 & 2.8 & 0.05 \\
\hline \multicolumn{2}{|l|}{ Any overlap } & 22.3 & 30.5 & 32.4 & 0.72 \\
\hline \multicolumn{2}{|c|}{ Scaffold total length, $\mathrm{mm}$} & $18.0(18.0-28.0)$ & $21.8(18.0-30.0)$ & $18.0(18.0-32.0)$ & 0.36 \\
\hline \multicolumn{2}{|c|}{ Scaffold diameter, mm } & $3.0(3.0-3.25)$ & $3.0(3.0-3.25)$ & $3.0(3.0-3.0)$ & 0.04 \\
\hline \multicolumn{2}{|c|}{ Implantation pressure, atm } & $12.5 \pm 3.2$ & $12.7 \pm 3.2$ & $13.2 \pm 2.6$ & 0.33 \\
\hline \multicolumn{2}{|c|}{ Post-dilation } & 75.6 & 75.4 & 83.2 & 0.50 \\
\hline \multicolumn{2}{|c|}{ Post-dilation balloon diameter, $\mathrm{mm}$} & $3.2 \pm 0.4$ & $3.2 \pm 0.4$ & $3.1 \pm 0.4$ & 0.02 \\
\hline Post-dilatation & re, atm & $17.7 \pm 0.4$ & $17.5 \pm 3.7$ & $16.0 \pm 2.6$ & 0.05 \\
\hline Final device/ref & ratio & $1.10(1.01-1.23)$ & $1.08(0.99-1.20)$ & $1.14(1.0-1.27)$ & 0.06 \\
\hline TIMI flow post & 0 & 0.1 & 0.1 & 0.0 & \\
\hline & 1 & 0.1 & 0.04 & 0.0 & 093 \\
\hline & 2 & 1.1 & 1.1 & 1.1 & 0.50 \\
\hline & 3 & 98.7 & 98.8 & 98.9 & \\
\hline Final diameter & & $13.0(7.0-18.0)$ & $13.0(8.0-18.0)$ & $17.8(13.6-21.8)$ & $<0.001$ \\
\hline
\end{tabular}

\section{PREDICTORS OF MACE}

Using multivariable logistic regression analysis, female sex, prior PCI, prior MI, scaffold/reference diameter ratio $>1.25$, residual stenosis $>15 \%$, and reference diameter $<2.5 \mathrm{~mm}$ were independent predictors of MACE at 30 days (Table 4). Acute coronary syndromes, dyslipidaemia, scaffold/reference diameter ratio $>1.25$, and residual stenosis $>15 \%$ were independent predictors of MACE, whereas intravascular imaging utilisation was associated with a reduction in MACE at long-term follow-up. As shown in Figure 2, optimal Absorb BVS implantation as assessed by angiography (i.e., scaffold/mean reference diameter ratio $<1.25$ and residual stenosis $<15 \%$ ) and intravascular imaging guidance (IVUS or OCT) were associated with lower MACE at long-term follow-up. 


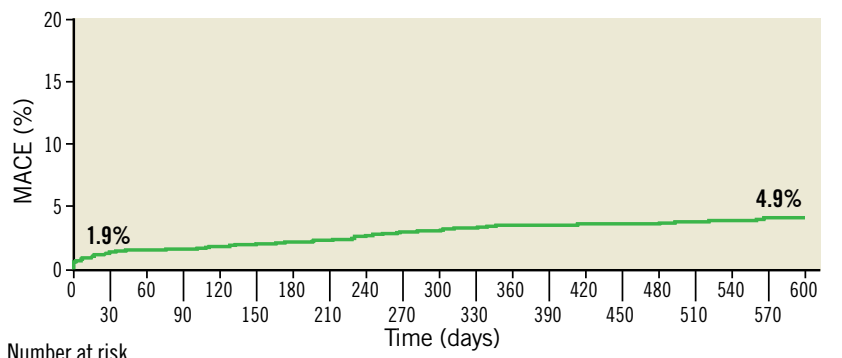

Number at risk

$\begin{array}{lllllllllll}1,881 & 1,404 & 1,383 & 1,344 & 1,278 & 1,257 & 1,224 & 1,110 & 1,085 & 1,060 & 984\end{array}$

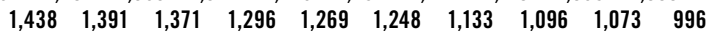

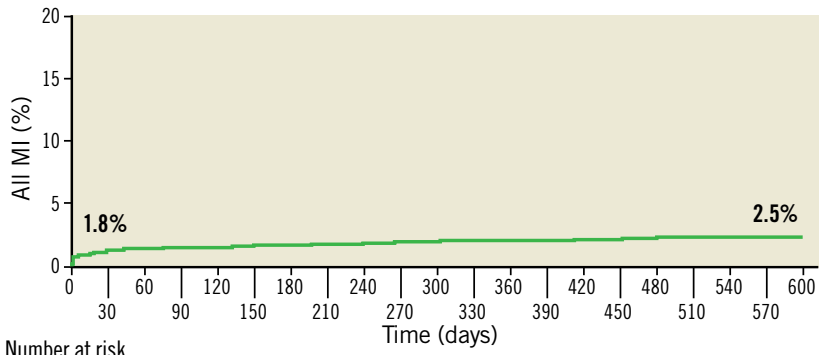
Number at risk

$\begin{array}{lllllllllll}1,855 & 1,401 & 1,381 & 1,350 & 1,292 & 1,275 & 1,246 & 1,132 & 1,106 & 1,080 & 1,005\end{array}$

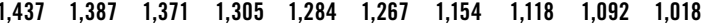

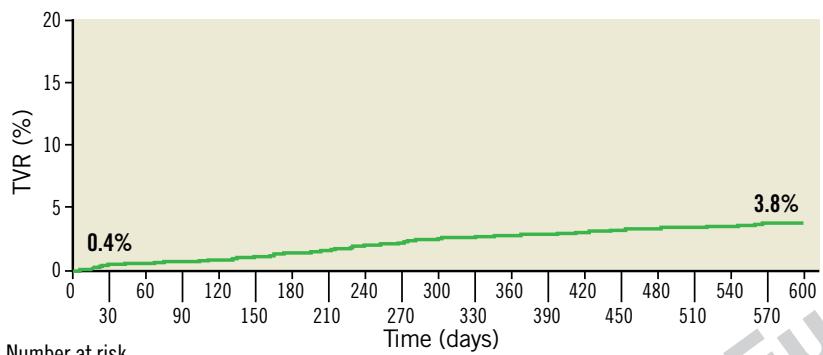

$\begin{array}{lllllllllll}1,912 & 1,352 & 1,322 & 1,283 & 1,219 & 1,198 & 1,176 & 1,099 & 1,077 & 1,052 & 978\end{array}$ $\begin{array}{lllllllll}1,446 & 1,330 & 1,311 & 1,237 & 1,210 & 1,189 & 1,120 & 1,086 & 1,064\end{array}$

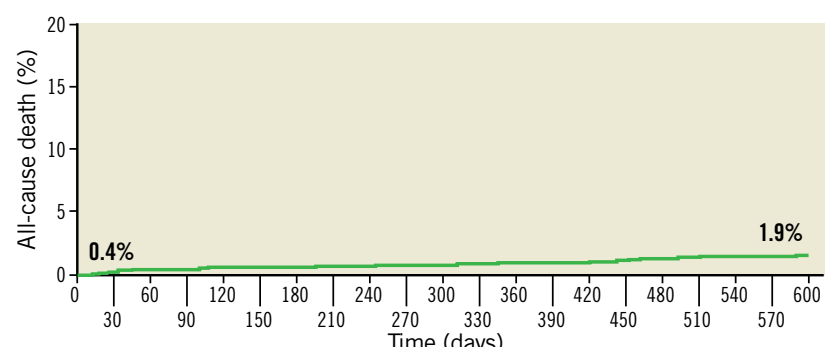

Number at risk

$\begin{array}{lllllllllll}1,889 & 1,428 & 1,409 & 1,378 & 1,321 & 1,304 & 1,271 & 1,182 & 1,144 & 1,113 & 1,029\end{array}$

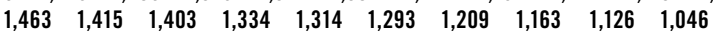

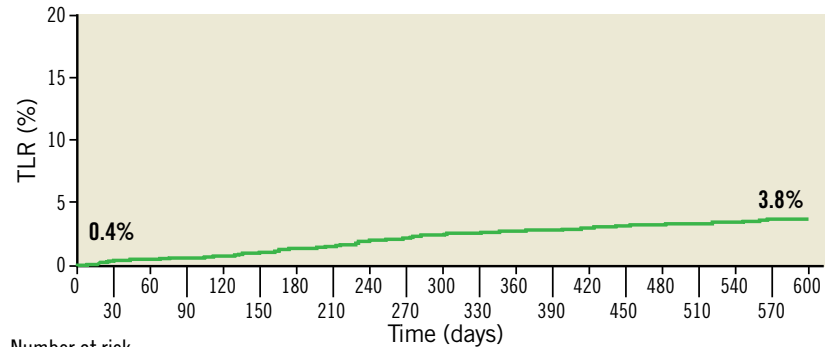

Number at risk

$\begin{array}{lllllllllll}1,912 & 1,352 & 1,322 & 1,283 & 1,219 & 1,198 & 1,176 & 1,099 & 1,077 & 1,052 & 978\end{array}$ $\begin{array}{llllllllll}1,446 & 1,330 & 1,311 & 1,237 & 1,210 & 1,189 & 1,120 & 1,086 & 1,064 & 988\end{array}$

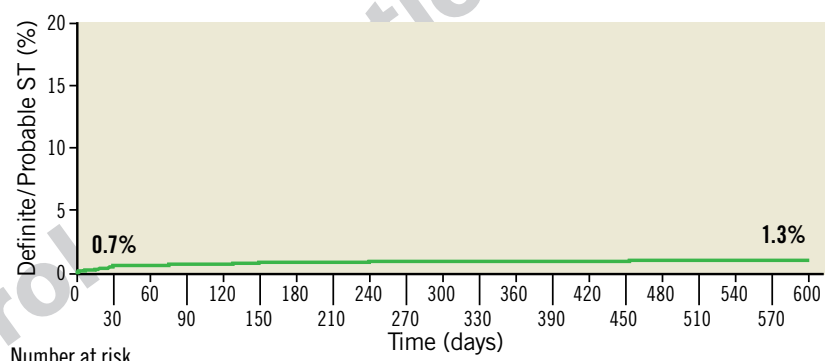

$\begin{array}{lllllllllll}1,909 & 1,348 & 1,320 & 1,287 & 1,230 & 1,214 & 1,196 & 1,123 & 1,100 & 1,076 & 1,006\end{array}$

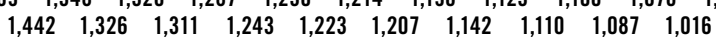

Figure 1. Kaplan-Meier curves for adverse events at 616 days. MACE: major adverse cardiac events; MI: myocardial infarction; ST: scaffold thrombosis; TLR: target lesion revascularisation; TVR: target vessel revascularisation

Table 3. Thirty-day and 1.7-year cumulative MACE in the overall population (1,933 patients).

\begin{tabular}{|l|r|}
\hline 30 days & $37(1.9 \%)$ \\
\hline MACE & $5(0.4 \%)$ \\
\hline All-cause death & $34(1.8 \%)$ \\
\hline Myocardial infarction & $8(0.4 \%)$ \\
\hline Target vessel revascularisation & $8(0.4 \%)$ \\
\hline Target lesion revascularisation & $13(0.7 \%)$ \\
\hline Definite/probable scaffold thrombosis & \\
\hline 1.7 years & $93(4.9 \%)$ \\
\hline MACE & $36(1.9 \%)$ \\
\hline All-cause death & $47(2.5 \%)$ \\
\hline Myocardial infarction & $72(3.8 \%)$ \\
\hline Target vessel revascularisation & $72(3.8 \%)$ \\
\hline Target lesion revascularisation & $26(1.3 \%)$ \\
\hline Definite/probable scaffold thrombosis & \\
\hline Values are n (\%). MACE: major adverse cardiac events &
\end{tabular}

Table 4. Independent clinical and angiographic predictors of MACE.

\begin{tabular}{|c|c|c|}
\hline & $\begin{array}{l}\text { Hazard ratio ( } 95 \% \\
\text { confidence interval) }\end{array}$ & $p$-value \\
\hline \multicolumn{3}{|l|}{30 days } \\
\hline Female & $3.60(2.68-4.82)$ & $<0.001$ \\
\hline Prior PCl & $1.49(1.07-1.95)$ & 0.01 \\
\hline Prior myocardial infarction & $3.05(2.27-4.09)$ & $<0.001$ \\
\hline Scaffold/reference ratio $>1.25$ & $2.48(1.19-5.18)$ & 0.01 \\
\hline Residual stenosis $>15 \%$ & $2.60(1.20-5.65)$ & 0.01 \\
\hline \multicolumn{3}{|l|}{1.7 years } \\
\hline Acute coronary syndrome & $2.79(1.47-5.29)$ & 0.002 \\
\hline Dyslipidaemia & $1.43(1.23-1.79)$ & 0.007 \\
\hline Scaffold/reference ratio $>1.25$ & $1.49(1.18-1.88)$ & 0.001 \\
\hline Residual stenosis >15\% & $1.67(1.34-2.07)$ & $<0.001$ \\
\hline Intravascular imaging use & $0.13(0.06-0.28)$ & $<0.001$ \\
\hline \multicolumn{3}{|c|}{$\begin{array}{l}\text { Scaffold/reference ratio and reference vessel diameter }<2.5 \mathrm{~mm} \text { were } \\
\text { variables in the regression models. In the } 2 \text { models scaffold/reference } \\
\text { ratio surpasses the importance of the small vessel diameter as a } \\
\text { predictor of MACE. MACE: major adverse cardiac events }\end{array}$} \\
\hline
\end{tabular}



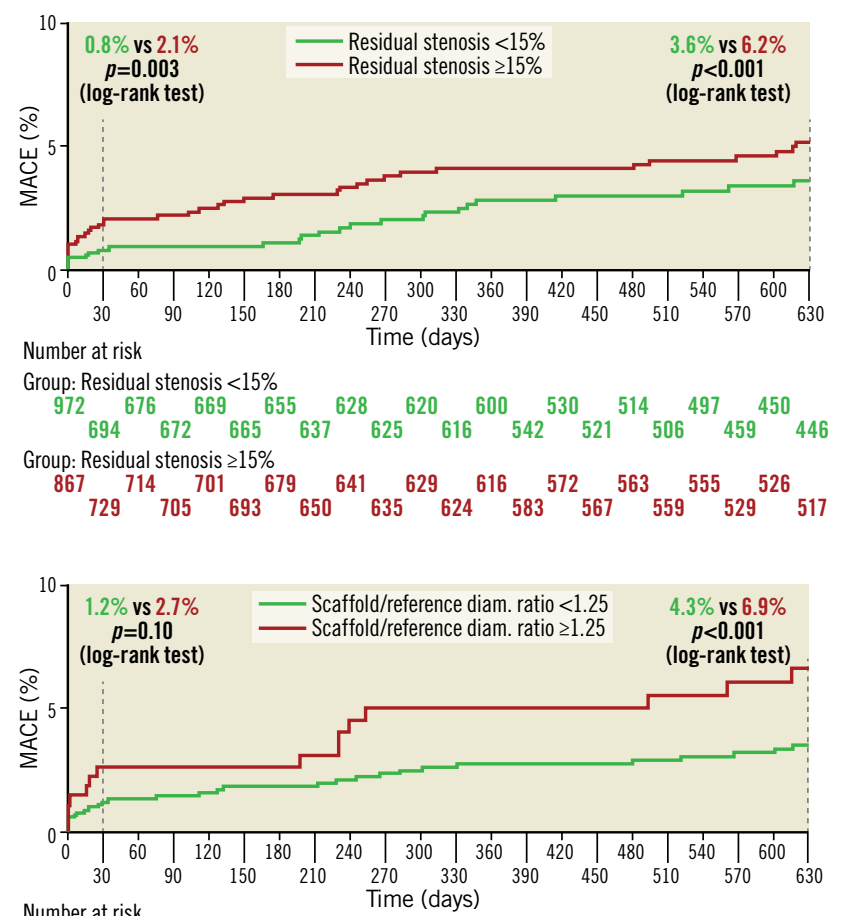

Group: Scaffold/reference diam. ratio $<1.25$

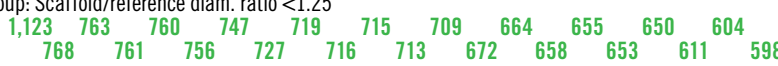

Group: Scaffold/reference diam. ratio $\geq 1.25$

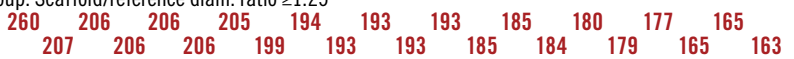

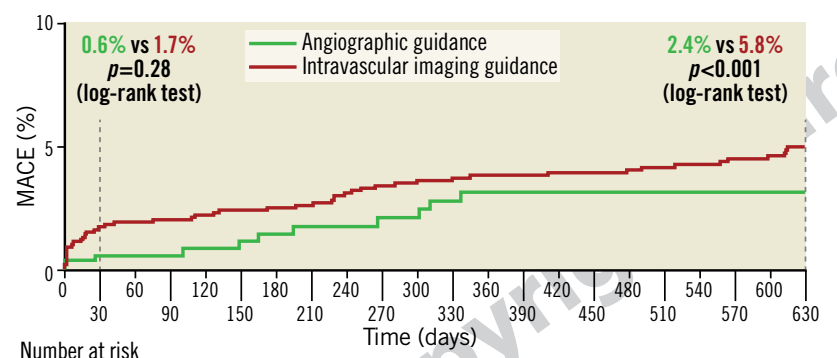

$$
\text { Number at risk }
$$

Group: Angiographic guidance

$\begin{array}{lllllllllll}1,382 & 1,040 & 1,031 & 1,011 & 979 & 972 & 959 & 892 & 876 & 865 & 818\end{array}$

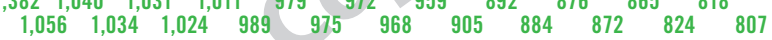
Group: Intravascular imaging guidance

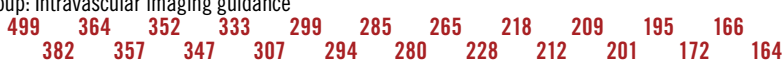

Figure 2. Kaplan-Meier curves for adverse events at 630 days according to the angiographic optimal criteria of Absorb BVS implantation and intravascular imaging use. Patients with optimal device implantation (scaffold/mean reference diameter ratio $<1.25$ and residual stenosis $<15 \%$ ) and intravascular imaging guidance had a significant reduction in major adverse cardiac events (MACE).

\section{Discussion}

The main findings of the present study, which includes mostly "real-world" Absorb BVS implantation, can be summarised as follows: 1) in high-volume centres with established experience with the Absorb BVS there was a relatively low rate of MACE and scaffold thrombosis; 2) female sex, prior PCI, prior MI, a high ratio between scaffold and reference vessel diameter, and residual stenosis were independently correlated with clinical events at 30 days; 3 ) acute coronary syndromes, dyslipidaemia, a high ratio between scaffold and reference diameter, and residual stenosis were independently correlated with clinical events at long-term follow-up. Intravascular imaging guidance was also associated with a significant reduction in MACE.

Absorb BVS have shown a number of potential advantages over DES. The absence of a rigid metallic cage may facilitate restoration of vessel vasomotor tone, adaptive shear stress, and late luminal enlargement, and may promote a preventive effect on atherosclerotic plaque progression ${ }^{3,12,13}$; however, recent evidence has raised concerns about BVS safety, mainly due to scaffold thrombosis. Absorb BVS implantation has been associated with a twofold to fourfold higher risk of device thrombosis compared with $\mathrm{EES}^{4-7}$. It has been reported that the risk of this harmful event is higher mainly between one and 30 days after implantation ${ }^{5,7,14,15}$. In the present series, however, use of the Absorb BVS in patients with a wide range of clinical and angiographic scenarios resulted in MACE in $1.9 \%$ and definite/probable device thrombosis in $0.7 \%$ at 30 days, and definite/probable device thrombosis in $1.3 \%$ at 1.7 years of follow-up.

The increased rate of events in the first month after implantation suggests that the different mechanical properties of the BVS may play a role in their occurrence. Polymeric BVS have about a 10 times lower tensile strength and six times lower elongation compared to DES ${ }^{16}$. Previous smaller studies have shown that Absorb BVS oversize and implantation in small (diameter $<2.5 \mathrm{~mm}$ ) vessels are associated with adverse clinical events ${ }^{8,17}$. Conversely, the current analysis showed that device-vessel mismatch, as assessed by angiography, surpasses the importance of small vessel diameter. Indeed, while implantation in vessels $<2.5 \mathrm{~mm}$ was only a univariate predictor, a scaffold/reference diameter ratio $>1.25$ was an independent predictor of 30-day MACE. As the smallest available diameter of the Absorb BVS is $2.5 \mathrm{~mm}$, its implantation in vessels $<2.5 \mathrm{~mm}$ should be considered a device-vessel mismatch. Of note, previous studies classified device mismatch when the proximal or distal maximal lumen diameter was larger than the implanted scaffold $^{17}$. In the present analysis, we assessed the ratio between device size and the mean (proximal and distal) reference diameter.

Another key factor connected with clinical events in our study was the presence of residual stenosis. This may be due to suboptimal scaffold expansion that may lead to a denser polymer surface pattern, flow disturbances, and microthrombus formation ${ }^{17,18}$. Considering that this polymeric device has a reduced mechanical strength in vivo compared to a metallic DES, our data emphasise the importance of diminishing the diameter stenosis as much as possible before Absorb BVS implantation. Although bench test results suggest comparable radial force for Absorb BVS and the metallic XIENCE DES (Abbott Vascular), quantitative coronary angiography analyses ${ }^{5,19,20}$ have demonstrated less acute gain, a smaller minimum lumen diameter, and greater residual stenosis after Absorb BVS implantation, most likely reflecting greater acute recoil. Appropriate vessel selection ( $>2.5 \mathrm{~mm}$ by visual estimation) 
and meticulous lesion preparation prior to Absorb BVS implantation, along with high-pressure balloon post-dilatation, have been strongly recommended to obtain optimal results and reduce MACE. A recent report ${ }^{8}$ has shown that, when an optimal Absorb BVSspecific implantation strategy was implemented in a "real-world" population, scaffold thrombosis rates fell from $3.3 \%$ to $1.0 \%$ at one year. Likewise, in the ABSORB III trial ${ }^{6}$ when the PSP protocol was used for scaffold implantation (predilation at a 1:1 balloon-toartery ratio with a non-compliant balloon that has been sized appropriately and routine post-dilation - up to $0.5 \mathrm{~mm}$ larger than the nominal scaffold diameter), better clinical outcomes were achieved.

In our analysis, intravascular imaging use (OCT or IVUS compared with angiography alone) was associated with a reduction in clinical events at long-term follow-up. Intravascular imaging guidance during Absorb BVS implantation has the potential to reduce both scaffold thrombosis and the need for repeat revascularisation. Appropriate vessel sizing and optimal scaffold expansion and apposition by imaging-guided PCI may explain its association with a lower event rate; however, the use of additional imaging modalities in this pooled database ( $\sim 30 \%$ of the cases) was left to operator discretion and was probably employed in patients with selected lesion/procedural characteristics. A dedicated randomised comparison on this matter should be explored in future studies.

Among several clinical, lesion, or procedure-related predictors of ST, early discontinuation of dual antiplatelet therapy (DAPT) is the most important factor for DES-associated late thrombosis. In a recent analysis by Felix at $\mathrm{al}^{21}$, DAPT discontinuation (between six and 18 months) following Absorb BVS implantation was potentially associated with scaffold thrombosis. This is one of the weaknesses of the present analysis, since information about DAPT compliance and the type of $\mathrm{P} 2 \mathrm{Y}_{12}$ used was not systematically collected.

\section{Limitations}

First, this is a post hoc analysis from multiple registries. Thus, the results of this study should be considered hypothesis-generating. Second, more than one third of the entire study population was from ABSORB EXTEND, a trial that included patients with lesion complexity considered at low-to-moderate risk for PCI. Therefore, our findings may be not representative of a truly "realworld" population. Threats to the external validity of the present analysis involve the interaction of the Absorb BVS with the specific types of patients included (low-to-moderate versus high-risk patients), the specific clinical setting (stable versus acute coronary syndromes), and the date when the patients were treated (earlier versus after more contemporary techniques of scaffold implantation were introduced). Third, event adjudication was conducted by individual study sites except for the ABSORB EXTEND, which had a dedicated clinical events committee. This may have caused variability in event definitions. Each participating centre did, however, apply the Academic Research Consortium definition of stent thrombosis ${ }^{11}$. Fourth, information about DAPT compliance and the type of $\mathrm{P} 2 \mathrm{Y}_{12}$ used (i.e., clopidogrel, prasugrel, or ticagrelor) was not specifically collected in our analysis. Fifth, there is no information about Absorb BVS penetration in each individual centre or about patient and lesion selection. Finally, although we adjusted for measured imbalances, we cannot completely rule out the possibility that not all multivariable correlates of MACE were identified. In addition, although multivariable models were created using a selection of relevant variables in order to avoid overfitting, the event per variable in the present analysis was less than recommended and thus the results should be interpreted with caution.

\section{Conclusions}

In this pooled analysis from a large-scale patient-level population, Absorb BVS implantation was associated with favourable clinical outcomes during both short- and long-term follow-up. Patient-related factors predicting the risk of MACE were comparable to those previously reported for metallic DES. Optimal Absorb BVS implantation and the use of intravascular imaging guidance are associated with lower rates of adverse events at long-term follow-up.

\section{Impact on daily practice}

The present study identified the clinical and procedural predictors of adverse events after Absorb BVS implantation. The analysis showed that device-vessel mismatch assessed by angiography surpasses the importance of small vessel diameter. A scaffold/reference diameter ratio $>1.25$ along with residual stenosis $>15 \%$ and non-use of intravascular imaging guidance were independent predictors of MACE at long-term follow-up.

\section{Guest Editor}

This paper was guest edited by Alec Vahanian, MD, PhD; Department of Cardiology, Hôpital Bichat-Claude Bernard, and University Paris VII, Paris, France.

\section{Conflict of interest statement}

A. Bartorelli has received speaker fees from Abbott Vascular. The other authors have no conflicts of interest to declare. The Guest Editor is a consultant for Edwards Lifesciences.

\section{References}

1. Otsuka F, Vorpahl M, Nakano M, Foerst J, Newell JB, Sakakura K, Kutys R, Ladich E, Finn AV, Kolodgie FD, Virmani R. Pathology of second-generation everolimus-eluting stents versus first-generation sirolimus- and paclitaxeleluting stents in humans. Circulation. 2014;129:211-23.

2. Dangas GD, Serruys PW, Kereiakes DJ, Hermiller J, Rizvi A, Newman W, Sudhir K, Smith RS Jr, Cao S, Theodoropoulos K, Cutlip DE, Lansky AJ, Stone GW. Meta-analysis of everolimus-eluting versus paclitaxel-eluting stents in coronary artery disease: final 3-year results of the SPIRIT clinical trials program (Clinical Evaluation of the Xience V Everolimus Eluting Coronary Stent System in the Treatment of Patients With De Novo Native Coronary Artery Lesions). JACC Cardiovasc Interv. 2013;6:914-22.

3. Serruys PW, Onuma Y, Garcia-Garcia HM, Muramatsu T, van Geuns RJ, de Bruyne B, Dudek D, Thuesen L, Smits PC, Chevalier B, McClean D, Koolen J, Windecker S, Whitbourn R, Meredith I, Dorange C, Veldhof S, Hebert KM, Rapoza R, Ormiston JA. Dynamics of vessel wall changes following the implantation of the absorb everolimus-eluting bioresorbable vascular scaffold: 
a multi-imaging modality study at $6,12,24$ and 36 months. EuroIntervention. 2014;9:1271-84.

4. Serruys PW, Chevalier B, Dudek D, Cequier A, Carrié D, Iniguez A, Dominici M, van der Schaaf RJ, Haude M, Wasungu L, Veldhof S, Peng L, Staehr P, Grundeken MJ, Ishibashi Y, Garcia-Garcia HM, Onuma Y. A bioresorbable everolimus-eluting scaffold versus a metallic everolimus-eluting stent for ischaemic heart disease caused by de-novo native coronary artery lesions (ABSORB II): an interim 1-year analysis of clinical and procedural secondary outcomes from a randomised controlled trial. Lancet. 2015;385: 43-54.

5. Ellis SG, Kereiakes DJ, Metzger DC, Caputo RP, Rizik DG, Teirstein PS, Litt MR, Kini A, Kabour A, Marx SO, Popma JJ, McGreevy R, Zhang Z, Simonton C, Stone GW; ABSORB III Investigators. Everolimus-Eluting Bioresorbable Scaffolds for Coronary Artery Disease. N Engl J Med. 2015; 373:1905-15.

6. Kereiakes DJ, Ellis SG, Metzger C, Caputo RP, Rizik DG, Teirstein PS, Litt MR, Kini A, Kabour A, Marx SO, Popma JJ, McGreevy R, Zhang Z, Simonton C, Stone GW; ABSORB III Investigators. 3-Year Clinical Outcomes With Everolimus-Eluting Bioresorbable Coronary Scaffolds: The ABSORB III Trial. J Am Coll Cardiol. 2017;70:2852-62.

7. Wykrzykowska J, Kraak RP, Hofma SH, van der Schaaf RJ, Arkenbout EK, IJsselmuiden AJ, Elias J, van Dongen IM, Tijssen RYG, Koch KT, Baan J, Vis M, de Winter RJ, Piek JJ, Tijssen JGP, Henriques JPS; AIDA Investigators. Bioresorbable Scaffolds versus Metallic Stents in Routine PCI. N Engl J Med. 2017;376:2319-28.

8. Puricel S, Arroyo D, Corpataux N, Baeriswyl G, Lehmann S, Kallinikou Z, Muller O, Allard L, Stauffer JC, Togni M, Goy JJ, Cook S. Comparison of everolimus- and biolimus-eluting coronary stents with everolimus-eluting bioresorbable vascular scaffolds. J Am Coll Cardiol. 2015;65:791-801.

9. Ellis SG, Cowley MJ, DiSciascio G, Deligonul U, Topol EJ, Bulle TM, Vandormael MG. Determinants of 2-year outcome after coronary angioplasty in patients with multivessel disease on the basis of comprehensive preprocedural evaluation. Implications for patient selection. The Multivessel Angioplasty Prognosis Study Group. Circulation. 1991;83:1905-14.

10. Abizaid A, Ribamar Costa J Jr, Bartorelli AL, Whitbourn R, van Geuns RJ, Chevalier B, Patel T, Seth A, Stuteville M, Dorange C, Cheong WF, Sudhir K, Serruys PW; ABSORB EXTEND investigators. The ABSORB EXTEND study: preliminary report of the twelve-month clinical outcomes in the first 512 patients enrolled. EuroIntervention. 2015;10:1396-401.

11. Cutlip DE, Windecker S, Mehran R, Boam A, Cohen DJ, van Es GA, Steg PG, Morel MA, Mauri L, Vranckx P, McFadden E, Lansky A, Hamon M, Krucoff MW, Serruys PW; Academic Research Consortium. Clinical end points in coronary stent trials: a case for standardized definitions. Circulation. 2007;115:2344-51.
12. Garcia-Garcia HM, Serruys PW, Campos CM, Onuma Y. Differential impact of five coronary devices on plaque size: insights from the ABSORB and SPIRIT trials. Int J Cardiol. 2014;175:441-5.

13. Garcia-Garcia HM, Serruys PW, Campos CM, Muramatsu T, Nakatani S, Zhang YJ, Onuma Y, Stone GW. Assessing bioresorbable coronary devices: methods and parameters. JACC Cardiovasc Imaging. 2014;7:1130-48.

14. Cassese S, Byrne RA, Ndrepepa G, Kufner S, Wiebe J, Repp J, Schunkert H, Fusaro M, Kimura T, Kastrati A. Everolimus-eluting bioresorbable vascular scaffolds versus everolimus-eluting metallic stents: a meta-analysis of randomised controlled trials. Lancet. 2016;387:537-44.

15. Stone GW, Gao R, Kimura T, Kereiakes DJ, Ellis SG, Onuma Y, Cheong WF, Jones-McMeans J, Su X, Zhang Z, Serruys PW. 1-year outcomes with the Absorb bioresorbable scaffold in patients with coronary artery disease: a patient-level, pooled meta-analysis. Lancet. 2016;387:1277-89.

16. Kereiakes DJ, Onuma Y, Serruys PW, Stone GW. Bioresorbable Vascular Scaffolds for Coronary Revascularization. Circulation. 2016;134:168-82.

17. Ishibashi Y, Nakatani S, Sotomi Y, Suwannasom P, Grundeken MJ, GarciaGarcia HM, Bartorelli AL, Whitbourn R, Chevalier B, Abizaid A, Ormiston JA, Rapoza RJ, Veldhof S, Onuma Y, Serruys PW. Relation Between Bioresorbable Scaffold Sizing Using QCA-Dmax and Clinical Outcomes at 1 Year in 1,232 Patients From 3 Study Cohorts (ABSORB Cohort B, ABSORB EXTEND, and ABSORB II). JACC Cardiovasc Interv. 2015;8:1715-26.

18. Bourantas CV, Papafaklis MI, Kotsia A, Farooq V, Muramatsu T, GomezLara J, Zhang YJ, Iqbal J, Kalatzis FG, Naka KK, Fotiadis DI, Dorange C, Wang J, Rapoza R, Garcia-Garcia HM, Onuma Y, Michalis LK, Serruys PW. Effect of the endothelial shear stress patterns on neointimal proliferation following drug-eluting bioresorbable vascular scaffold implantation: an optical coherence tomography study. JACC Cardiovasc Interv. 2014;7:315-24.

19. Gomez-Lara J, Brugaletta S, Farooq V, van Geuns RJ, De Bruyne B, Windecker S, McClean D, Thuesen L, Dudek D, Koolen J, Whitbourn R, Smits PC, Chevalier B, Morel MA, Dorange C, Veldhof S, Rapoza R, GarciaGarcia HM, Ormiston JA, Serruys PW. Angiographic geometric changes of the lumen arterial wall after bioresorbable vascular scaffolds and metallic platform stents at 1-year follow-up. JACC Cardiovasc Interv. 2011;4:789-99.

20. Gao R, Yang Y, Han Y, Huo Y, Chen J, Yu B, Su X, Li L, Kuo HC, Ying SW, Cheong WF, Zhang Y, Xu B, Popma JJ, Stone GW; ABSORB China Investigators. Bioresorbable Vascular Scaffolds Versus Metallic Stents in Patients With Coronary Artery Disease: ABSORB China Trial. J Am Coll Cardiol. 2015;66:2298-309.

21. Felix CM, Vlachojannis GJ, IJsselmuiden AJJ, Fam JM, Smits PC, Lansink WJ, Diletti R, Zijlstra F, Regar ES, Boersma E, Onuma Y, van Geuns RJM. Potentially increased incidence of scaffold thrombosis in patients treated with Absorb BVS who terminated DAPT before 18 months. EuroIntervention. 2017;13:e177-84. 